\section{Similarity and liking}

\author{
DAVID S. DUSTIN and BARBARA ALFONSIN \\ New York State University College, Plattsburgh, N.Y. 12901
}

A random sample of 99 statements was drawn from two family autobiographies. One group of college women rated the extent to which the author of each statement appeared similar to themselves. Another group rated their liking for the author of each statement. The item means of these two ratings correlated $.51(\mathrm{p}<.01)$, in accord with prediction. A third rating, that of the intimacy of the information contained in each statement, was unreleated to either of the other ratings.

Many studies have shown that the extent to which a person perceives an other to be similar to himself is positively related to his liking for that other (see Byrne. 1969). Although most of these studies have dealt with similarity of attitudes, some have used similarity of economic status, of defense mechanisms, of self-concept, of needs, of abilities, and of emotional responses.

One purpose of the present study was to determine the similarity-liking relationship, not for any one selected type of information, but for a random sample of information about persons. The usual positive relationship was predicted.

A second purpose was to determine if a relationship existed between the intimacy of the information one has about another and one"s liking for him. Worthy, Gary, \& Kahn (1969) found that Ss tended to like others who chose to communicate more intimate information about themselves more than they liked others who chose to communicate less intimate information. Those authors' interpretation was that the liking was caused by the fact that the other chose to communicate intimate information, not by the information itself. In the present study, the possibility was investigated that the intimacy of information about an other, even if communicated through no choice of the other, is related to liking.

\section{METHOD}

The population of information represented in this study was the population of statements about own actions, feelings, and perceptions made by the speakers in The Children of Sanchez (Lewis, 1961) and Pedro Martinez (Lewis, 1964). 1 . These are autobiographies of two lower-class Mexican families, the former urban and the latter peasant. Since the material presented about the members of these two families is extensive, as well as accurately recorded (by tape recorder), these books seemed to comprise one of the best available populations of information about a few individuals.

Excluding the father, who speaks relatively briefly, there are two men and two women in The Children of Sanchez and two men and one woman in Pedro Martinez. The material spoken by each person was sampled at a rate that would produce a total sample of approximately 14 pages for each. On each sampled page, the first sentence in which the speaker told about his own actions, feelings, or perceptions was selected. Any parts of the selected sentences that were not clear when the sentences were removed from contex were rewritten. Some examples of the statements used are:

"I left politics and took up the Gospel."

"Sometimes I borrowed a bicycle and rode over to a bar near my aunt's house."

"When it comes to love, I don't understand my own actions."

The resulting 99 sentences were arranged in mixed order and divided into three groups of 33. Each of the three groups of sentences was duplicated in three forms, for rating liking, similarity, and intimacy (deep/superficial), respectively. The instructions on each form stated that each piece of information was given by a different person, and asked Ss to rate each item on a 5-step scale. On one form, Ss were instructed to rate how much they guessed they might like or dislike the person speaking. On another, they were asked to indicate whether the information given made the speaker appear to be similar or dissimilar to them. On the third, they were instructed to indicate whether the information revealed something deep about the person speaking or something more superficial. The resulting nine forms were distributed in repeating order, one form per $S$, to several freshman psychology classes, and were filled out during class time.

\section{RESULTS}

The forms filled out by men were discarded, because there were not enough male Ss for a separate analysis. The number of women who rated each item on each form ranged from 21 to 25 . The mean of the women's ratings for each item on each of the nine forms was computed. When the mean ratings for the 99 items were correlated, Pearson $r$ for liking and similarity was .51 , for liking and intimacy was .09 , and for similarity and intimacy was .00. With an $\mathrm{N}$ of 99 , only the liking-similarity relationship was significant $(\mathrm{p}<.01)$.

\section{CONCLUSIONS}

The expected similarity-liking relationship was obtained, even for this random sample of information about persons in a culture and class different from those of the Ss. This finding extends the generality of the similarity-liking relationship.

The absence of a significant relationship between liking and intimacy tends to support the interpretation by Worthy, Gary, \& Kahn (1969) that in their study it was the choice to communicate more intimate information, not merely the nature of the information itself, that produced liking.

\section{REFERENCES}

BYRNE, D. Attitudes and attraction. In $L$. Berkowitz (Ed.), Advances in experimentol social psychology. Vol.4. New York: Academic Press, 1969. Pp. 36-89.

LEWIS, O. The children of Sanchez. (Paperback) New York: Vintage Books, 1961.

LEWIS, O. Pedro Martinez. New York: Random House, 1964.

WORTHY, M., GARY, A. L., \& KAHN, G. M. Self-disclosure as an exchange process. Journal of Personality \& Social Psychology, 1969, 13, 59-63.

\section{NOTE}

1. The authors wish to thank Random House, Inc. for permission to use these copyrighted materials in this study. 